\title{
T helper 17 cells in the pathophysiology of acute and chronic kidney disease
}

\author{
David P. Basile, Md Mahbub Ullah, Jason A. Collet, Purvi Mehrotra \\ Department of Anatomy, Cell Biology \& Physiology, Indiana University of Medicine, Indianapolis, IN, United States
}

\begin{abstract}
Both acute and chronic kidney disease have a strong underlying inflammatory component. This review focuses primarily on T helper 17 (Th17) cells as mediators of inflammation and their potential to modulate acute and chronic kidney disease. We provide updated information on factors and signaling pathways that promote Th17 cell differentiation with specific reference to kidney disease. We highlight numerous clinical studies that have investigated Th17 cells in the setting of human kidney disease and provide updated summaries from various experimental animal models of kidney disease indicating an important role for Th17 cells in renal fibrosis and hypertension. We focus on the pleiotropic effects of Th17 cells in different renal cell types as potentially relevant to the pathogenesis of kidney disease. Finally, we highlight studies that present contrasting roles for Th17 cells in kidney disease progression.
\end{abstract}

Keywords: Acute kidney injury, Fibrosis, Hypertension, Inflammation

\section{Background}

As of 2017, the global burden of chronic kidney disease (CKD) was estimated to be approximately $9.1 \%$, indicating that CKD is a significant healthcare concern worldwide. Global age-adjusted mortality rates for patients with CKD have declined in the last 30 years, and quality of life metrics decrease as glomerular filtration rate declines [1]. In the period between 1990 and 2017, there was an approximate $41 \%$ increase in the number of patients with end-stage renal disease (ESRD). Despite this, CKD patients are more likely to die due to complications such as hypertension, cardiovascular disease, anemia, and bone and mineral disorders, and these patients also have an increased cancer incidence [1].

Acute kidney injury (AKI), generally defined as a rapid loss of kidney function, results in renal damage caused by factors such as nephrotoxins, radiocontrast agents, hypoperfusion, surgery, sepsis, and antibiotics [2]. AKI occurs in up to $7 \%$ of hospital admissions per year in the United States [2-4], while a recent study based on KDIGO (Kidney Disease: Improving Global Outcomes) guidelines suggested that up to 1 in 5 adult hospitalized patients worldwide have some form of AKI [5]. AKI is associated with significant morbidity and mortality $[4,6,7]$, and surviving patients are at increased risk of developing CKD and ESRD [8].

Received: October 12, 2020; Revised: November 13, 2020; Accepted: November 13, 2020

Editor: Ming-Zhi Zhang, Vanderbilt University, Nashville, TN, USA

Correspondence: Dabid P. Basile

Department of Anatomy, Cell Biology \& Physiology, Indiana University School of Medicine, 635 Barnhill Dr. MS 2063, Indianapolis, IN 46202,

United States. E-mail:dpbasile@iupui.edu

ORCID: https://orcid.org/0000-0003-4649-3464

Copyright ( 2021 by The Korean Society of Nephrology

(a) This is an Open Access article distributed under the terms of the Creative Commons Attribution Non-Commercial and No Derivatives License (http:// creativecommons.org/licenses/by-nc-nd/4.0/) which permits unrestricted non-commercial use, distribution of the material without any modifications, and reproduction in any medium, provided the original works properly cited. 
Both acute and CKD have a strong underlying inflammatory component. The purpose of this review is to focus primarily on T helper 17 (Th17) cells as mediators of inflammation and present evidence that these cells modulate both acute and CKD and that the primary cytokine produced by these cells, interleukin (IL) 17A, is a potential therapeutic target in kidney disease.

\section{T helper 17 definition and roles}

CD4+ T cells have pleiotropic potential and are thought to assist in the humoral immune response indirectly by affecting innate immune cells such as neutrophils and macrophages. T-cell activation occurs when T-cell receptors (TCRs) recognize specific peptides on $\mathrm{MHCII}+$ antigen presenting cells (APCs). Coupled with co-stimulatory signals derived from APCs, as well as cytokines and other signals from innate immune cells, these combined inputs drive T-cell differentiation and expansion. In 1986, Mosmann et al. [9] defined two distinct sets of T-helper cells based on their lymphokine profiles; Th1 and Th2 cells. The transcription factors T-bet and STAT-1 are essential for the differentiation of Thl cells, characterized by the secretion of interferon (IFN) $-\gamma$, IL-2, IL-12, and tumor necrosis factor (TNF)- $\alpha$. The primary function of Thl cells is to assist in the macrophage response against intracellular pathogens such as viruses or bacteria [10]. In contrast, STAT-6 and GATA3 drive differentiation of Th2 cells, characterized by the secretion of IL- 4 as well as IL-10, IL-13, and IL-25 [11]. A primary function of Th2 cells in immune responses is to fight extracellular parasites by regulating mucous production in the gastrointestinal tract and stimulating antibody production to facilitate destruction of invading parasites by eosinophils or mast cells [10].

In 2005, two groups described a population of T-helper cells referred to as Th17 cells based on the expression of the signature cytokine IL-17A. These cells also secrete other factors such as IL-17F, IL-21, IL-22, IL-23, and TNF- $\alpha$ [12-14]. Th17 cells play a critical role in host protection against certain types of pathogens such as extracellular bacteria, which are not traditional targets of Th1 or Th2 cells [10]. Under the influence of IL-17A, Th17 cells are strongly proinflammatory, resulting in an influx of neutrophils to fight infections [14].

Like Th1 and Th2 cells, Th17 cells differentiate from naïve Th0 cells following engagement of TCRs and the influence of local cytokines (reviewed in $[15,16])$. This response is dependent on the expression of RAR-related orphan receptor gamma $\mathrm{T}(\mathrm{ROR} \gamma \mathrm{t})$, the key transcriptional regulator of Th17 cell differentiation. This process is dependent on the proinflammatory cytokine IL- 6 and the activation of STAT3. Other proinflammatory cytokines, such as IL-21, can also activate STAT3 to induce expression of ROR $\gamma \mathrm{t}$ (Fig. 1). In addition, transcription factors such as basic leucine zipper ATF-like transcription factor or interferon regulatory factor 4 can modulate the chromatin accessibility of Th17 specific genes and act cooperatively with ROR $\gamma$ t to modulate Th17 differentiation [17]. Th17 differentiation is also thought to be dependent on the activity of transforming growth factor (TGF) $-\beta$, since $T G F \beta$ null mice, or mice that express a dominant negative form of T $\beta$ RII on CD4+ cells, lack the ability to produce mature Th17 cells, while mice overexpressing TGF- $\beta$ display enhanced Th17 activation [16].

Calcium signaling is induced following TCR stimulation, which is critical in driving the differentiation response. Several studies have indicated an important role for the store-operated calcium release activated calcium channel (CRAC) Orial in Th17 differentiation. Activation of this channel is dependent on depletion of endoplasmic reticulum stores of $\mathrm{Ca}^{2+}$ secondary to TCR activation, which is sensed by the endoplasmic reticulum transmembrane protein Stiml and its subsequent interaction with plasma membrane Orail to mediate enhanced $\mathrm{Ca}^{2+}$ influx (Fig. 1) $[18,19]$. Mutations in either Orail or Stim1 result in a severe combined immunodeficiency phenotype [20]. Kim et al. [21] identified putative Orail inhibitors that showed greater selectivity in abrogating Th17 differentiation vs. Th1 or Th2 differentiation by screening a chemical library. Orail inhibition also reduced the nuclear accumulation of nuclear factor of activated T cells and ROR $\gamma \mathrm{T}$. We suggested a requirement for Orail in Th17 differentiation in our recent study of a rat model of kidney injury; IL-17 expression by CD4+ cells was exclusive to those cells that expressed Orail and was not detected in CD4+ cells that lacked expression of this channel [22].

The IL-17 receptor family comprises five members; IL-17RA, IL-17RB, IL-17RC, IL1-7RD, and IL-17RE. The primary ligands secreted by Th17 cells, IL-17A and IL-17F, form homodimers or IL-17A/F heterodimers and engage primarily with IL17RA, but likely require complex formation with IL-17RC for efficient binding or signal transduction (for a detailed 


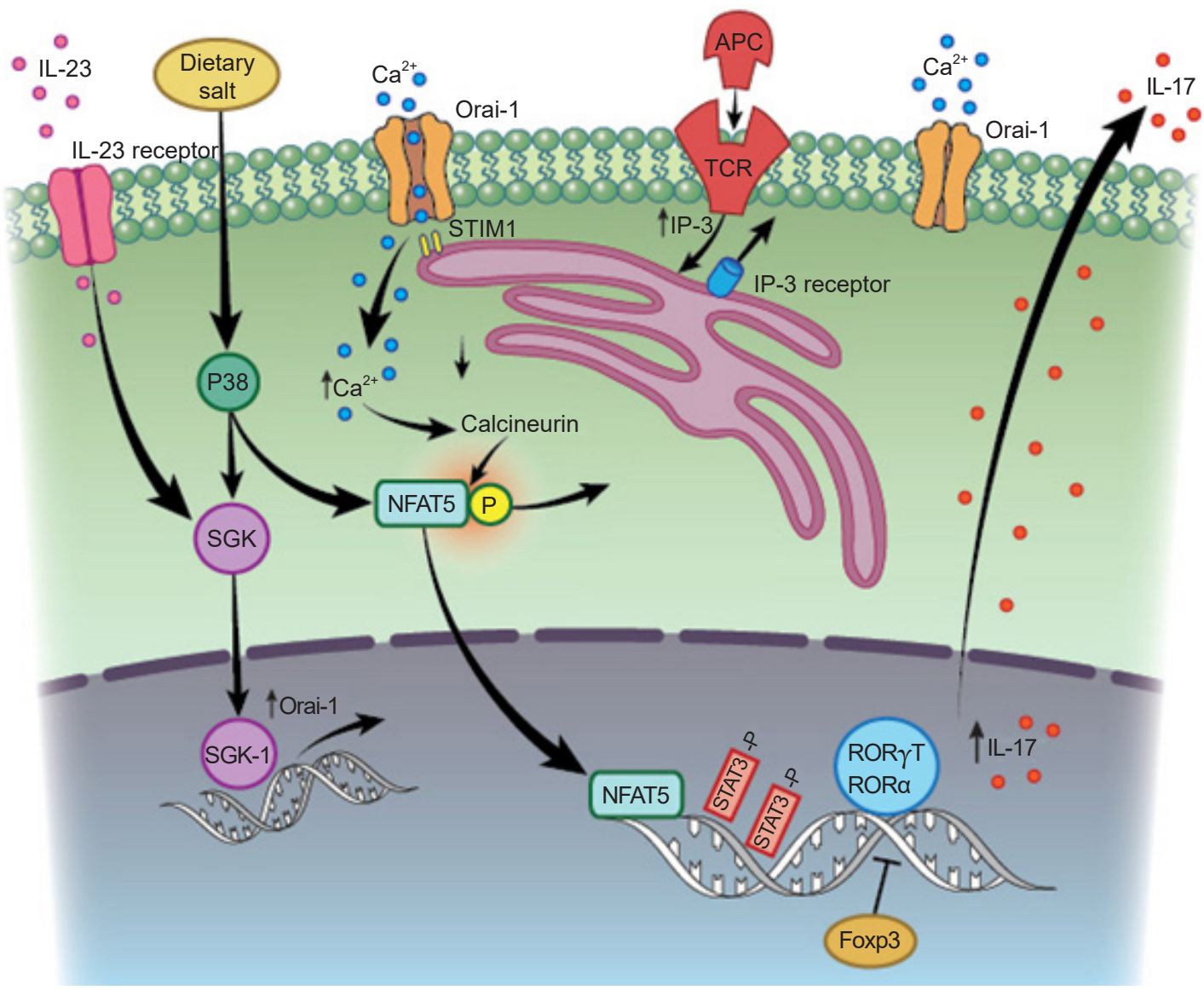

Figure 1. Activation and differentiation of T helper 17 (Th17) cells in the setting of renal injury and potential influence of salt. Th17 cell differentiation and interleukin (IL) 17 activation occur secondary to T-cell receptor (TCR) activation. Activation of STAT3 is required for induction of the transcription factor RAR-related orphan receptor gamma T (RORYT), which mediates transcription of the signature cytokine, IL-17. The process appears to be dependent on activation of the store-operated calcium release activated calcium (CRAC) channel Oria-1, which is initially activated by stromal interaction molecule 1 (STIM1) following endoplasmic reticulum depletion of Ca ${ }^{2+}$. The sustained elevation of $\mathrm{Ca}^{2+}$ mediated by Oria1 activates nuclear factor of activated T cells (NFAT) dephosphorylation and further drives IL-17 expression. Oria1 is also activated by a high-salt environment, possibly resulting from serine/threonine-protein kinase (SGK) signaling, which may further amplify Th17 activity in the setting of elevated dietary sodium intake.

APC, antigen presenting cells; IP-3, inositol 1,4,5-trisphosphate.

review see [23]). A complex pattern of differing affinities of IL-17A, IL-17F, and IL-17A/F for different receptors, as well as different ratios of IL-17RA and IL-17RC present in different cell types have been proposed to account for tissuespecific responses [24]. Importantly, Kuestner et al. [25] demonstrated that a soluble IL17RC-Fc fusion protein was able to bind to both IL-17A and IL-17F, an approach that was shown to inhibit the activity of both of these ligands in vivo.

\section{Role of interleukin 17 in kidney pathophysiology}

IL-17 receptors are expressed in many different cell types but are prominent in cells of hematopoietic origin [24]. Because the kidney is vulnerable to infection, Th17 cells are thought to serve a critical role in antimicrobial host defense $[26,27]$. IL-17 is among a number of factors that are elevated in patients with acute urinary tract infections (UTIs) [28]. Increased expression of IL-17A was observed in the bladders of mice infected with uropathogenic Escherichia coli. Furthermore, $I L 17 A^{-/}$mice have reduced macrophage and neutrophil influx, resulting in impaired clearance of bacterial load [29]. Interestingly, Olson et al. [30] demonstrated increased UTI severity in male mice vs. female mice and suggested that sex differences in UTI 
outcomes were due to a greater IL-17 response in females than males [31]. In a model of systemic Candida albicans infection, infected mice were shown to have increased IL-17 expression while null $I L 17 R A^{-/}$mice showed increased renal fungal colonization, reduced neutrophil infiltration, and decreased survival [32]. An interesting study by Ramani et al. [33] demonstrated that tubular specific deletion of IL17RA was essential for activation of host defenses in response to $C$. albicans infection, suggesting that IL-17 expressed by renal parenchymal cells plays a role in fighting infections.

\section{Autoimmune and inflammatory diseases}

While the Th17 system plays an important role in hostdefense, unrestrained or inappropriate IL-17 signaling may exacerbate tissue damage due to its strong proinflammatory properties. Accumulating evidence suggests that Th17 cells or increased IL-17 expression is a common feature of many kidney diseases (Table 1 [22,28,34-59]). For example in the setting of autoimmune disease, although initially considered the result of Th1-mediated effects, hyper-activation of Th17 cells (or potentially other IL-17-secreting cells) has been suggested to exacerbate conditions such as psoriasis, inflammatory bowel disease, and autoimmune encephalitis [60].

Systemic lupus erythematosus (SLE) is an autoimmune disorder characterized by the production of auto-antibodies. Th17 cells have been proposed to mediate the interaction between immune complexes and alterations in kidney structure and function [61]. Lupus patients have been shown to have more circulating CD4+/IL-17+ cells than control patients [34], and circulating IL-17 levels were shown to be higher in patients with active rejection than those in a nonrejection state and were undetectable in healthy control patients [35]. Another study reported that baseline levels of IL-17 and IL-23 in SLE patients predicted a poor response to treatment [36].

Similarly, Krebs et al. [38] demonstrated higher levels of kidney ROR $\gamma \mathrm{t}+\mathrm{T}$ cells in patients with antineutrophil cytoplasmic antibody (ANCA)-associated glomerular nephritis. Patients with acute ANCA vasculitis had higher circulating IL-17 and IL-23 than healthy controls, and these levels remained persistently elevated above those in control patients even after inflammation resolved [40]. IL17 immunostaining was identified in renal biopsies from patients with ANCA nephritis, although positively-stained cells were initially identified as polymorphonuclear granulocytes with lower frequencies of IL-17+ T cells [39]. Both serum and urinary levels of IL-17 have been shown to be elevated in patients with immunoglobulin A (IgA)-nephropathy (IgAN) [41], another immune complex-mediated disease triggered by mesangial deposition of IgA leading to CKD.

Data from multiple mouse models support the hypothesis that Th17 cells contribute to inflammatory disease progression. These mouse models include crescentic glomerular nephritis following myeloperoxidase injection [62,63]; exposure to the Goodpasture antigen, $\alpha 3 \mathrm{IV}-\mathrm{NC1}$ [64]; lupus nephritis induced by pristane injection [65]; and injection of anti-glomerular basement membrane antibody [38]. Th17 cell accumulation in the inflamed kidneys was reported for all these models. Furthermore, reduced prevalence of kidney disease was observed in studies that used $I L 17 A^{-/-}$mice or $r o r \gamma t^{--}$mice [66] relative to wild-type mice. The protection was associated with reduced infiltration of other cells such as neutrophils and macrophages and the expression of cytokines such as C-C motif chemokine ligand (CCL) 5.

Paust et al. [67] examined the dynamics of both Th1 and Th17 cells following injection of sheep serum into mice to induce glomerular inflammation. Th17 cells peaked in the earlier phase of the disease (i.e., 10 days following injection), while Thl cells peaked during the later phase of the disease (>20 days). Null mutations or immunoneutralization of either IL-17 or IFN $\gamma$ reduced the degree of renal dysfunction and tissue injury, while adoptive transfer of wild-type splenocytes, but not $I L 17^{-/}$or $I F N^{/-}$derived splenocytes, sutained the degree of renal damage in T-cell-deficient $\mathrm{Ragl}^{-1}$ mice. Interestingly, adoptive transfer of Th17 cells primed by glomerular antigens into $\operatorname{Rag}^{-/-}$mice was sufficient to drive the formation of glomerular crescents [68].

Infiltration of Th17 cells into the kidney is due in part to local expression of cytokines. Using the MRL/lpr model of lupus nephritis, Steinmetz et al. [69] reported an influx of both Th1 and Th17 cells that appeared to be dependent on the activity of CXCR3 on CD4 cells, as mutation of this receptor reduced infiltration of both Th1 and Th17 cells. CXCR3 interacts with at least three ligands, Mig/CXCL9, IP10/CXCL10, and ITAC/CXCL11, suggesting that these may play a role in Th17 infiltration. Lu et al. [70] demonstrated that incubation of human mesangial cells with serum from IgAN patients stimulated the production of CCL20. 
Table 1. Interleukin (IL) 17 expression in kidney diseases and hypertension

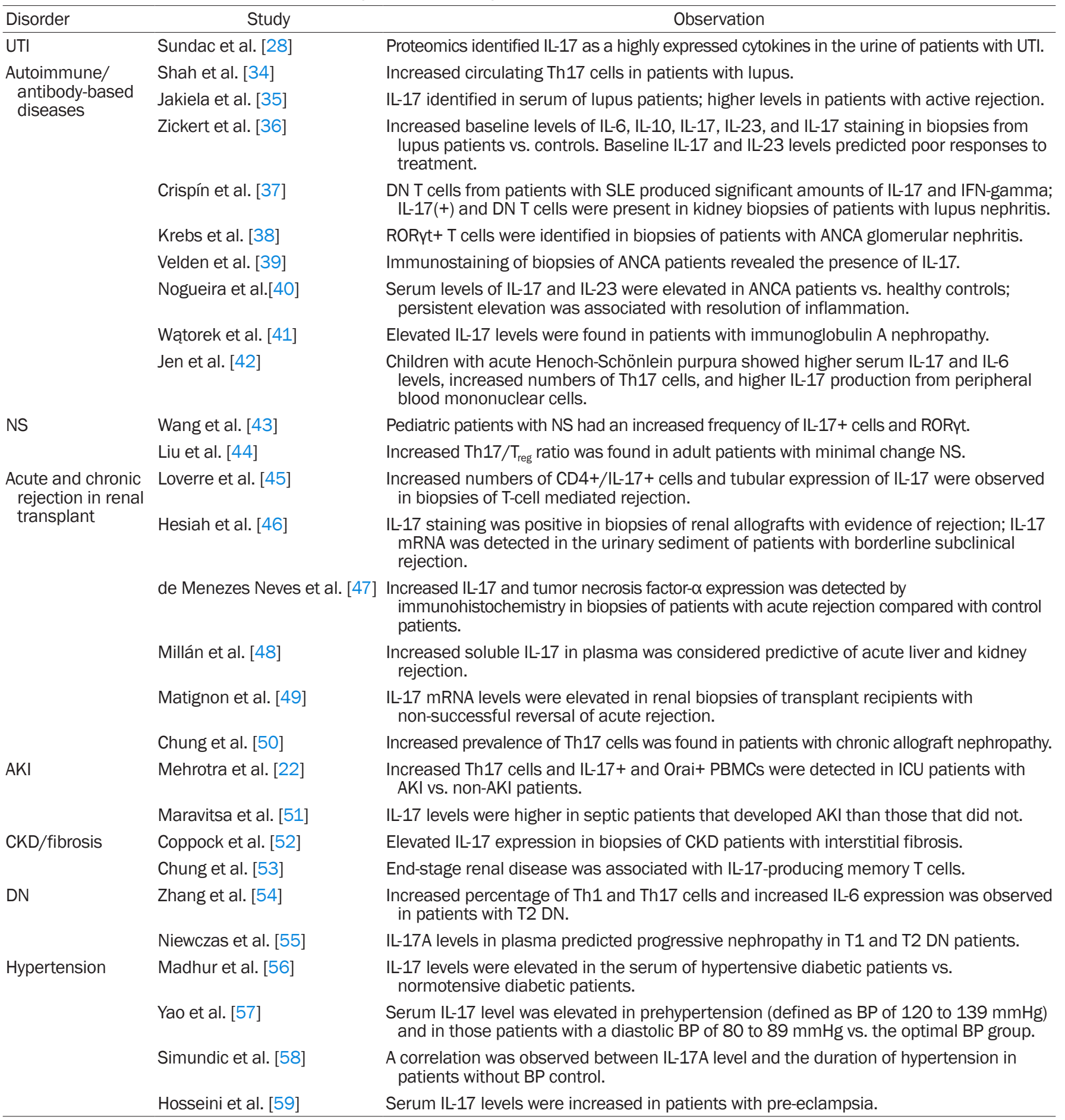

AKI, acute kidney injury; ANCA, antineutrophil cytoplasmic antibody; BP, blood pressure; CKD, chronic kidney disease; DN, diabetic nephropathy; ICU, intensive care unit; mRNA, messenger RNA; NS, nephrotic syndrome; PBMC, peripheral blood mononuclear cell; RORyt, RAR-related orphan receptor gamma T; SLE, systemic lupus erythematosus; Th, T-helper cell; $\mathrm{T}_{\text {reg, }}$ T-regulatory; UTI, urinary tract infection. 
Through interaction with its cognate receptor chemokine receptor 6 (CCR6), CCL20 was shown to be chemo-attractant to IL-17+CD3+ T cells in transwell experiments. These IL-17+ T cells showed enhanced expression of CCR6, and immunofluorescence staining identified a population of CD3+IL-17+CCR6+ cells in kidneys of IgAN patients but not in control kidney samples [70]. In the study of Paust et al. [67], infiltration of Th17 cells was attributed to an early increase in the expression of CCL20. Using a method dependent on a photo-convertible fluorescent protein in Kaede mice, Th17 cells were shown to traffic from the gut to the kidney in response to ANCA exposure. The migration of Th17 cells was dependent on the activity of the CCL20/CCR6 axis, and the severity of the disease and infiltration of Th17 cells could be up- or down-modulated by treatments that affected resident gut $\mathrm{T}$ cells [38].

\section{Complications in renal transplantation}

The Th17 system has also been suggested to contribute to rejection of solid organ transplants. Acute allograft rejection is initiated by alloreactive $\mathrm{T}$ cells primed in secondary lymphoid organs and recruited to the graft. There is increasing evidence that IL-17 expression in local tissue is associated with allograft rejection $[71,72]$. In the setting of kidney transplantation, IL-17 was identified by immunohistochemistry in biopsies of patients with acute rejection compared with control patients, while levels of Foxp3, a marker of T-regulatory $\left(\mathrm{T}_{\text {reg }}\right)$ cells that inhibits Th17 cells via the activity of IL-10, were reduced $[46,47]$. Chronic IL-17 expression in tubular epithelial cells was also shown to be associated with acute antibodymediated rejection [45]. Some studies have suggested that outcomes in acute rejection are dependent on the degree of Th17 activation. For example, Millán et al. [48] showed that circulating IL-17 levels and the percentage of IFN$\gamma^{+} \mathrm{CD}^{+} \mathrm{CD}^{+} 9^{+}$and IFN $\gamma^{+} \mathrm{CD} 8^{+} \mathrm{CD} 69^{+}$cells could identify patients at high risk of acute rejection following either liver or kidney transplantation. Matignon et al. [49] demonstrated that elevated IL-17 messenger RNA (mRNA) in renal biopsies of elderly transplant recipients was associated with nonsuccessful reversal of acute rejection. Recently, NovaLamperti et al. [73] demonstrated that tolerant recipients had fewer Th17 cells than patients with chronic rejection, while isolated peripheral blood mononuclear cells (PBMCs) from tolerant transplant recipients manifested reduced TCR signaling and Th17 differentiation compared to PBMCs from patients developing chronic rejection.

Evidence from animal models further supports a role for IL-17 in transplant rejection [46]. In models of cardiac or liver allograft rejection, increased expression of IL-17 by both CD4 and CD8 cells was observed, and an imbalance in Th17/Treg cells was shown to be associated with allograft rejection [74-76]. In a liver model of allograft transplantation, immunoneutralization of IL-17 improved expression of $\mathrm{T}_{\text {reg }}$ cells and liver survival [75], while $I L 17^{\wedge}$ mice exhibited increased $\mathrm{T}_{\text {reg }}$ expression and survival following cardiac allograft transplant surgery [76].

Patients with chronic allograft nephropathy showed an increase in prevalence of Th17 cells following renal transplantation [50]. Mortazavi et al. [77] demonstrated that immunosuppressive therapy was associated with an improved Th17/ $\mathrm{T}_{\text {reg }}$ balance. Abadja et al. [78] demonstrated that mycophenolate has a stronger Th17 inhibitory effect than tacrolimus in in vitro activated human CD4 cells. In addition, these investigators showed that patients treated with both mycophenolate and low doses of tacrolimus had lower circulating levels of IL-17 than patients treated with tacrolimus alone. Low vitamin D levels have been shown to inversely correlate with Th17 cells in transplant recipients, and calcitriol supplementation was shown to suppress Th17 cells relative to treatment with tacrolimus alone [79]. These data suggest a role for Th17 cell responses in graft outcomes.

\section{Responses in acute injury}

As described above, T-lymphocytes as well as other immune cells are known to play roles in autoimmune and immunemediated diseases as well as complications from renal transplant. However, other kidney disorders, such as acute injury, hypertensive and diabetic nephropathy, and the development of interstitial fibrosis, have a complicated pathophysiology that entails cellular responses to injury secondary to hypoxia, toxins, or elevated pressures, alterations in hemodynamics, activation of fibrogenic factors, and interstitial remodeling. Studies over the past few years have shown that the immune system plays a previously unappreciated role as a modulator of primary pathophysiological processes in these different types of kidney disease.

For example, AKI is a significant clinical disorder resulting 
from renal ischemia or nephrotoxic injury. While damage to the renal microvasculature or tubular epithelium is the primary component in the pathogenesis of AKI [2], the potential role of inflammation as a modulator of renal injury has received significant attention over the last 15 years [80]. Yokota et al. [81] published several seminal studies describing the importance of lymphocytes as mediators of renal injury. Studies from this group using STAT4 $4^{--}$mice suggested a potential role for Thl in the pathogenesis of AKI, while studies using $S T A T 6^{--}$mice suggested a potential role for Th2-derived IL-4 in protection from renal injury [82].

Recently, the potential contribution of Th17 cells to AKI has been examined. Our group demonstrated an increase in circulating IL-17+ PBMC and Th17 (CD4+IL-17+) cells in patients of intensive care unit after diagnosis of AKI vs. critically ill patients without AKI [22], while Maravitsa et al. [51] reported that IL-17 levels were increased in septic patients that developed AKI. Using a rat model of renal ischemia/reperfusion (I/R) injury, our research group demonstrated that Th17 cells were the predominant T-helper subtype present in the kidney following acute injury, peaking between 1 to 3 days post I/R but remaining persistently elevated for several weeks following recovery from I/R. Worsening AKI in rats that were placed on a vitamin D-deficient diet was associated with an increased number of Th17 cells and a decreased number of $\mathrm{T}_{\text {reg }}$ cells compared to rats on a standard diet [83]. Treatment with sIL17RC or the store-operated $\mathrm{Ca}^{2+}$ entry channel (SOCC) inhibitor YM58483 blocked Th17 induction and significantly attenuated the development of renal injury [22,84]. Similar increases in Th17 cells in response to I/R injury have been reported in mice, while T-cell specific STAT3 deletion attenuated Th17 activation and resulted in protection against I/R [85]. In addition, rats with a mutation of the gene encoding ROR $\gamma \mathrm{t}$ showed impaired Th17 responses but not Th1 or Th2 responses, and were protected from renal injury by I/R [86]. In other models of AKI, such as the cecal-ligation puncture model of sepsis, $I L 17^{\prime}$ mice showed reduced renal cytokine expression, neutrophil infiltration, and tubular injury relative to wild-type mice [87]. Chan et al. [88] demonstrated reduced injury in response to cisplatin treatment in $I L 17^{\prime-}$ mice and Roryt $t^{\prime-}$ mice, while our group demonstrated that Th17 blockade protected against AKI in glycerol-induced rhabdomyolysis [22]. The influx of Th17 cells in the setting of AKI may be due in part to the activation of CCL20 [88]. In addition, a recent study suggests that damaged renal tubules produce IL-17C, which may recruit Th17 cells to promote inflammation via binding to the receptor IL-17RE [89]. The precise mechanisms by which Th17 cells contribute to renal injury are not clear, but are likely related to an overall inflammatory response leading to recruitment of effectors cells or contributions to vascular congestion and hypoxia.

Effective recovery from AKI is a result of a tissue repair response. However, incomplete or ineffective repair may predispose to the secondary development of CKD. The AKIto-CKD transition may result from persistent alterations in vascular, tubular, and/or interstitial compartments [90]. Our group recently proposed a central role for persistent Th17 activity in this process. An AKI-to-CKD transition model was established by exposing rats to a high-salt diet after 5 weeks of recovery from I/R injury. This procedure, which hastened the development of inflammation, fibrosis, and hypertension, also potently stimulated the re-expression of Th17 cells [91]. CKD progression and hypertension in response to high-salt treatment was attenuated by mycophenolate, which also blocks induction of Th17 cells [84,92]. Th17 activation and CKD progression were also blocked by treatment with losartan or the SOCC inhibitor YM58483 [22,84]. Interestingly, the AKI-to-CKD transition in athymic nude rats, which lack conventional Th17-cells but display a compensatory increase in IL-17 production by natural killer cells (NK cells; CD3-/CD161+), was also blocked by sIL17RC [84].

\section{Chronic kidney disease, fibrosis, and hypertension}

Biopsies of patients with renal fibrosis showed elevated renal IL-17 expression [52], while other studies have identified polymorphisms within the ILI7E and IL17RA genes associated with ESRD [93]. CKD models associated with interstitial fibrosis, such as the unilateral ureteral obstruction (UUO) model [52,94-97] or adriamycin-induced nephropathy, are characterized by elevations in renal Th17 cells [98]. In all of these studies, strategies to neutralize of IL-17 activity, either with antibodies or by using $I L 17^{\prime}$ mice, mitigated the degree of renal fibrosis in these models. The fibrotic effect of IL-17 may be modulated by other cytokines. For example, the activity of the IL-17/IL-23 axis in inducing renal fibrosis was diminished in animals that lacked IL-36 
receptors [94], while $I L 27^{\prime-}$ mice showed increased Th17induced fibrosis in response to UUO [99].

Diabetic nephropathy is known to have a strong inflammatory component and the role of Thl7 cells in this setting has received significant attention in recent years [100]. Patients with type II diabetic nephropathy show a skew toward circulating Thl and Th17 cells and have increased serum levels of IL-6 and IL-17, correlated with renal albumin excretion [54]. A recent study of both type 1 and 2 diabetes patients demonstrated that IL$17 \mathrm{~A}$ and IL-17F were among a panel of proinflammatory cytokines that could predict CKD progression [55]. In addition to other studies that have demonstrated that Th17 cells may contribute to pancreatic beta cell destruction [101], these observations suggest an important role for Th17 cells in diabetic nephropathy.

In streptozotocin-induced diabetes, mycophenolate treatment reduced Th17 cell infiltration into the kidney and alleviated the development of albuminuria and renal fibrosis without effects on glycemic control [102], while $I L 17^{\prime}{ }^{-}$mice, or mice treated with anti-IL-17 antibody were protected from the development of proteinuria and renal scarring [103]. Recently, Lavoz et al. [104] reported similar results; IL-17A immunoneutralization attenuated renal dysfunction and disease progression in BTBR ob/ob mice.

Renal inflammation also plays an important role in the development of hypertension $[105,106]$. Recent studies identified elevated levels of circulating IL-17 in patients with prehypertension, defined as a systolic BP of 120 139 [57]. In diabetic patients, IL-17 was elevated in those with hypertension vs. those without hypertension [56]. In another study of patients without blood pressure control, a correlation was observed between IL-17A level and the duration of hypertension [58].

Multiple animal models support the hypothesis that lymphocytes contribute to the development of hypertension. Genetic deletion of the Ragl gene in Dahl salt-sensitive (S) rats resulted in depletion of mature T and B cells and a reduction in salt-sensitive hypertension [107]. In models of chronic angiotensin II (Ang II)-induced hypertension, the initial increase in blood pressure in response to Ang II infusion appeared largely independent of inflammation. However, sustained infusion of Ang II for up to 3 weeks in rats on a high-salt diet or in Dahl S rats resulted in increased renal lymphocyte accumulation, while mycophenolate treatment significantly abrogated the development of hypertension and renal fibrosis [108].

In C57BL/6J mice, Ang II infusion increased the percentage of circulating Th17 cells and IL-17A. IL17A ${ }^{-/}$mice showed similar elevations in blood pressure in the first 2 weeks of Ang II infusion as wild-type mice, but developed less severe hypertension $(\sim 30 \mathrm{mmHg})$ and reduced inflammation during the subsequent 2 weeks of infusion [56]. Similarly, Wade et al. [109] reported that treatment with sIL17RC attenuated the degree of hypertension in Ang II-infused Dahl $\mathrm{S}$ rats. These data suggest that Thl7 activation contributes to the full development of hypertension in Ang II-dependent models.

In other models, Amador et al. [110] demonstrated that mineralocorticoid-dependent hypertension was associated with activation of Th17 cells and the down-regulation of Foxp3 expression, while immuno-neutralization of IL-17 significantly attenuated the degree of hypertension and renal damage. Chiasson et al. demonstrated that the calcineurin inhibitor cyclosporine A increased expression of Th17 cells and decreased expression of $\mathrm{T}_{\text {reg }}$ cells. The resultant increase in systolic blood pressure and impaired endothelial dependent vasodilation in isolated blood vessels was reversed by treatment with an anti-IL-17 antibody [111]. Finally, increased circulating levels of IL-17 have been demonstrated in patients with pre-eclampsia [59]. In a pregnant reduced uterine perfusion pressure (RUPP) rat model of pre-eclampsia, infusion of sIL17RC significantly attenuated the development of hypertension [112].

It has been suggested that renal injury and antigen presentation promote activation of adaptive immune responses in the setting of hypertension or following acute injury (reviewed in $[105,106,113])$. Other physiological factors may influence the degree of lymphocyte activation and modulate Th17 responses. For example, increased dietary salt intake has been shown to increase Th17 expression not only in models of kidney injury, but also other models of Th17-dependent inflammation [114-117], suggesting that the effect of dietary salt is not dependent exclusively on kidney damage. In vitro studies demonstrated that elevated extracellular sodium concentration can hasten differentiation of naïve Th0 cells to a Th17 phenotype in vitro [118]. It has been suggested that a high-salt diet can increase $\mathrm{Na}+$ deposition in extracellular glycosaminoglycans in the skin, which has been postulated to increase local $\mathrm{Na}$ concentration relative to extracellular fluid [119]. 
Our group demonstrated that Ang II in combination with elevated extracellular sodium (170 $\mathrm{mM}$ ) synergistically enhanced IL-17 production in CD4+ lymphocytes isolated from post-ischemic kidneys [91]. In addition, losartan dramatically attenuated Th17 cell accumulation in response to a high-salt diet following ischemic AKI, suggesting that the Ang II pathway contributes directly to activation of these cells [91]. Recent studies have shown that patients with saltlosing tubulopathies have reduced skin sodium content associated with reduced Th17 activation and impaired immune responses. It was suggested that an altered ionic environment resulted in reduced Th17 cells activity as lymphocytes from these patients were able to activate the Th17 pathway in vitro in response to extracellular sodium [120]. These studies further indicate that sodium status has a direct impact on the activation of Th17 cells.

\section{Effects of interleukin 17 effects on different renal cell types promote alterations in renal function and the development of fibrosis}

The role of Th17 cells likely varies in different types of kidney disease due to underlying differences in the etiology of various kidney diseases and the highly pleiotropic nature of IL-17A. As described above, IL-17 receptors are localized in neutrophils, which contribute to the strong proinflammatory effect of Th17 cells in inflammatory conditions. However, the precise roles of Th17 cells in different kidney diseases remain to be fully elucidated. As part of this process, an appreciation of the different cell types with the potential to be influenced by IL-17A is required.

To date, few studies have directly evaluated the presence of IL-17 receptors in the various cell types of the kidney. However, gene profiling studies are providing insight into the dynamics of IL-17-IL-17R expression. For example, Liu et al. [121] utilized a transgenic RNA-translating ribosome affinity purification (TRAP) approach to profile genes in a cell-type specific fashion in response to I/R injury. By incorporating Cre-specific promoters to drive tagged ribosomal protein expression, RNA isolated from tagged ribosomes was used for cell specific gene profiling. A search of the Gene Expression Omnibus (GEO) public data set utilized in this study [121] indicated that the highest baseline (i.e., noninjury) expression of IL-17RA mRNA was in the epithelial compartment. However, following renal I/R injury, relative
IL-17RA mRNA expression was significantly induced by $\sim 2.5, \sim 4$, and $\sim 6$-fold in interstitial, endothelial, and myeloidderived cells, respectively. Therefore, in addition to its effects on neutrophils, the expression of IL-17 receptors on multiple cell types points to a complex role for IL-17 in renal pathophysiology (Fig. 2).

\section{Effects on epithelial cells}

IL-17 likely mediates blood pressure responses in part by regulating renal sodium transporters in the epithelium. Norlander et al. [122] demonstrated that IL-17A upregulation secondary to angiotensin infusion increased the expression of the sodium hydrogen exchanger-3 (NHE 3) and the sodium chloride cotransporter (NCC). IL-17A treatment of mouse distal convoluted tubules or human proximal tubule cells in vitro also increased expression of these sodium transporters, which was dependent on the phosphorylation of serine/threonine-protein kinase (SGK)-1 [122]. In vivo, mice exhibited impaired diuresis and natriuresis responses to acute saline loads following chronic Ang II infusion, and this was significantly attenuated in $I L 17 A^{-/-}$mice [123]. Damaged tubules also play an important role in the activation of inflammatory pathways leading to renal fibrosis [124,125], and IL-17 activity may contribute to this effect. In vitro studies of proximal tubule cells demonstrated that IL-17 stimulation increased the expression of profibrotic molecules and the production of IL-6 and IL-8, in part via activation of extracellular signal-regulated kinase $1 / 2$ phosphorylation $[50,126]$. It is unclear if elevated IL-17 is sufficient to induce elevated blood pressure responses or if it serves to modulate other sodium-retaining factors to effect hypertension.

\section{Effects on endothelial cells and vascular smooth muscle cells}

Immune cells in the kidney may represent a source of oxidant stress. IL-17 has been shown to impair endothelial nitric oxide synthase activity, suggesting that altered vascular activity may also contribute to the development of hypertension [114,127]. A recent study by Orejudo et al. [128] suggested that vascular remodeling of small arteries is influenced by IL-17A. In this study, IL-17 induced hypertrophy of vascular smooth muscle cells in vitro, while IL-17 administration in mice increased blood pressure and 


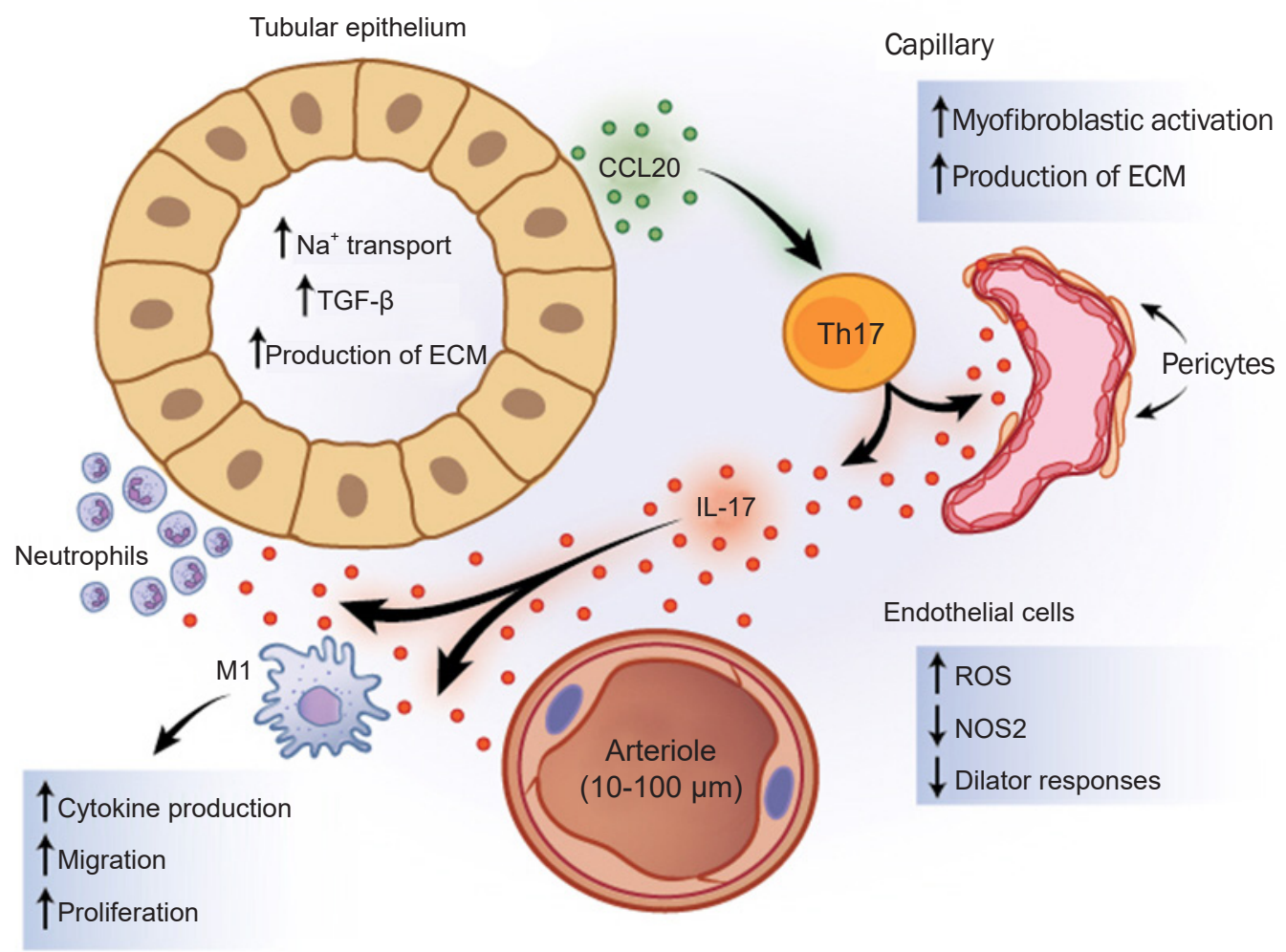

Figure 2. Pleiotropic effects of T helper 17 (Th17) cells on the development of interstitial fibrosis and the development of hypertension. Cytokines released from injured kidney tissue, such as C-C motif chemokine ligand 20 (CCL20), may be chemoattractants for Th17 cells. Interleukin (IL) 17 release in the milieu of the kidney has the potential to influence fibrosis and hypertension by interacting with a number of cell types. IL-17 receptors are present on hematopoietic, epithelial, endothelial, and smooth muscle cells, as well as pericytes and fibroblasts. In tubules, IL-17 can stimulate activities associated with inflammatory cell recruitment, matrix accumulation, and enhanced sodium reabsorption. Pericytes or smooth muscle cells may acquire a more myofibroblastic phenotype. Evidence from endothelial cells and smooth muscle cells suggests that IL-17 may alter the regulation of vascular tone. Finally, IL-17 may have stimulatory or inhibitory effects on the inflammatory activation of macrophages and neutrophils depending on timing and context.

ECM, extracellular matrix; TGF, transforming growth factor; ROS, reactive oxygen species; NOS, nitric oxide synthase.

induced inward remodeling of small mesenteric vessels. Hydralazine normalized blood pressure but had no effect on the inward remodeling induced by IL-17 [128]. IL-17 also stimulates endothelial cells to promote neutrophil recruitment by activation of p38MAPK and STAT3 $[129,130]$. In brainderived endothelial cells, TNF- $\alpha$ and IL-17 increased the production of CCL2 and CXCL1; other cytokines including CCL20 and IL-17 facilitated the migration of Th17 cells through the endothelial monolayer [131].

Activation of smooth muscle-like pericytes is considered to play a central role in the development of interstitial fibrosis [132]. No studies have directly evaluated the effects of IL-17 on renal pericytes or myofibroblasts in the setting of kidney disease. However, Th17 cells play a key role in asthma, and
IL-17 has been shown to direct remodeling of airway smooth muscle [133]. Studies of pericytes and smooth muscle cells from other organs suggest that these cells are highly responsive to IL-17. Gene array analysis of human aortic smooth muscle cells found that over 30 genes, including inflammatory cytokines and chemokines, were stimulated by incubation with IL-17 [56]. Cultured dermal or placental microvascular pericytes stimulated with IL-17 produced soluble factors that enhanced neutrophil migration and stabilized pericyte/ neutrophil interactions [134,135].

\section{Effects on macrophages}

In a model of wound healing, IL-17 administration increased 
inflammation, aggravated fibrogenic scar formation, and delayed wound healing. Blockade of macrophages with clodronate reduced the inflammatory response to IL-17 and improved wound healing [136]. Ge et al. [137] investigated the effects of macrophage-specific deletion of IL-17RA in a model of UUO and demonstrated reduced accumulation of monocytes and renal fibrosis. It is unclear whether IL-17 influences macrophage polarization. One study reported that IL-17 stimulation of human monocytes did not alter M1/M2 markers but rather increased the expression of costimulatory molecules and proinflammatory cytokines in response to stimulation with oxidized low-density lipoprotein [138]. However, other studies suggested that IL17 may mediate M2 polarization, consistent with an antiinflammatory/pro-repair or fibrotic phenotype $[139,140]$.

\section{Beneficial effects of interleukin 17 on outcomes in kidney disease models}

While the majority of evidence suggests that inappropriate activation of Th17 cells enhances inflammation and contributes to acute and CKD, these data should be viewed with caution, since several studies have reported that IL17 may be protective in renal disease. Inhibition of IL-17 was reported to aggravate renal injury and fibrosis in a UUO model [141] and response to DOCA-salt/Ang II-induced hypertension [142]. An in vitro study demonstrated that IL17 inhibited TGF- $\beta$ stimulation of renal fibroblasts from $I L 17^{/}$mice following UUO [143]. Overexpression of IL-17 by adenovirus reduced inflammation and renal fibrosis, which was suggested to be the result of the local kallikreinkinin system altering the balance of extracellular matrixdegrading enzymes [96]. In C57BL6/lpr mice, a model of SLE, mutation of IL-17 blocked development of the SLE phenotype, but resulted in a significant lymphoproliferative disease characterized by splenomegaly and the expansion of total and double-negative T cells [144].

Mohamed et al. [145] showed that IL-17A levels in patients were reduced in advanced stages of diabetic kidney disease. In a streptozotocin model, IL-17A deficiency resulted in more severe disease progression relative to wild-type mice, and administration of low dose IL-17A reduced macrophage infiltration and the development of renal fibrosis. In our laboratory, ROR $\gamma \mathrm{t}$ mutant rats showed reduced sensitivity to AKI following I/R vs. wild-types rats. However, an increase in ischemic time in $\mathrm{ROR} \gamma \mathrm{t}$ mutants resulted in failure to recover from AKI [86]. Administration of IL-17A facilitated recovery of postischemic ROR $\gamma \mathrm{t}$ mutant rats to a similar state as wildtype controls. Recovery from AKI due to IL-17 treatment was associated with inhibition of M1 macrophage infiltration, which remained elevated in untreated ROR $\gamma \mathrm{T}$ mutant rats for up to 4 days following I/R [86]. Taken together, these data suggest that the balance of Th17 cells plays an important role in immune homeostasis and may play an unappreciated role in feedback to suppress inflammation under some experimental conditions.

\section{Concluding remarks}

Since the discovery of Th17 cells, an important contributory role for these cells in kidney injury and fibrosis has been identified. We reviewed the accumulated research data implicating Th17 activation in models of kidney disease and hypertension. In addition, we outlined evidence that the primary cytokine produced by Th17 cells, IL-17A, may interact with multiple inflammatory and resident cells to drive disease. Due to its pleiotropic effects on multiple target cell types (outlined in Fig. 2), IL-17 is an attractive therapeutic target in several kidney disorders. Several reviews have addressed potential strategies to target IL-17 in disease, and biologic agents are already in use for treatment of diseases such as psoriasis [146]. An addition to biologics, other agents directed at SOCCs, which influence Th17 activation, are under development [147] and it is conceivable that such interventions may have therapeutic efficacy in patients with kidney disorders.

\section{Conflicts of interest}

All authors have no conflicts of interest to declare.

\section{Funding}

Work from the authors presented in this paper was supported by National Institutes of Health grant DK-063114 and a Bridge Funding award from the Indiana University Research Foundation (DPB). Purvi Mehrotra was supported by an Indiana University Showalter Fellowship. 


\section{Authors' contributions}

\section{Conceptualization: All authors}

Writing-original draft: All authors

Writing-review \& editing: All authors

All authors read and approved the final manuscript.

\section{Acknowledgements}

We would like to thank Dr. Robert Bacallao for critical review of this manuscript and Ms. Barbara Sturonas-Brown for assistance with illustrations.

\section{ORCID}

David P. Basile, https://orcid.org/0000-0003-4649-3464

Md Mahbub Ullah, https://orcid.org/0000-0002-5712-6750

Jason A. Collet, https://orcid.org/0000-0002-0492-0926

Purvi Mehrotra, https://orcid.org/0000-0003-3102-4358

\section{References}

1. Webster AC, Nagler EV, Morton RL, Masson P. Chronic kidney disease. Lancet 2017;389:1238-1252.

2. Basile DP, Anderson MD, Sutton TA. Pathophysiology of acute kidney injury. Compr Physiol 2012;2:1303-1353.

3. Chertow GM, Soroko SH, Paganini EP, et al. Mortality after acute renal failure: models for prognostic stratification and risk adjustment. Kidney Int 2006;70:1120-1126.

4. Chertow GM, Burdick E, Honour M, Bonventre JV, Bates DW. Acute kidney injury, mortality, length of stay, and costs in hospitalized patients. J Am Soc Nephrol 2005;16:3365-3370.

5. Susantitaphong P, Cruz DN, Cerda J, et al. World incidence of AKI: a meta-analysis. Clin J Am Soc Nephrol 2013;8:1482-1493.

6. Zager RA, Baltes LA, Sharma HM, Jurkowitz MS. Responses of the ischemic acute renal failure kidney to additional ischemic events. Kidney Int 1984;26:689-700.

7. Bonventre JV, Basile D, Liu KD, et al. AKI: a path forward. Clin J Am Soc Nephrol 2013;8:1606-1608.

8. Coca SG, Singanamala S, Parikh CR. Chronic kidney disease after acute kidney injury: a systematic review and meta-analysis. Kidney Int 2012;81:442-448.

9. Mosmann TR, Cherwinski H, Bond MW, Giedlin MA, Coffman RL. Two types of murine helper T cell clone. I. Definition according to profiles of lymphokine activities and secreted proteins. J Immunol
1986;136:2348-2357.

10. Ruterbusch M, Pruner KB, Shehata L, Pepper M. In vivo cd4+ $\mathrm{T}$ cell differentiation and function: revisiting the Th1/Th2 paradigm. Annu Rev Immunol 2020;38:705-725.

11. Yu SL, Kuan WP, Wong CK, Li EK, Tam LS. Immunopathological roles of cytokines, chemokines, signaling molecules, and pattern-recognition receptors in systemic lupus erythematosus. Clin Dev Immunol 2012;2012:715190.

12. Harrington LE, Hatton RD, Mangan PR, et al. Interleukin 17-producing CD4+ effector T cells develop via a lineage distinct from the Thelper type 1 and 2 lineages. Nat Immunol 2005;6:11231132.

13. Park $\mathrm{H}, \mathrm{Li} \mathrm{Z}$, Yang XO, et al. A distinct lineage of CD4 T cells regulates tissue inflammation by producing interleukin 17. Nat Immunol 2005;6:1133-1141.

14. McGeachy MJ, Cua DJ, Gaffen SL. The IL-17 family of cytokines in health and disease. Immunity 2019;50:892-906.

15. Bhaumik S, Basu R. Cellular and molecular dynamics of Th17 differentiation and its developmental plasticity in the intestinal immune response. Front Immunol 2017;8:254.

16. Zhang S. The role of transforming growth factor $\beta$ in T helper 17 differentiation. Immunology 2018;155:24-35.

17. Ciofani M, Madar A, Galan C, et al. A validated regulatory network for Th17 cell specification. Cell 2012;151:289-303.

18. Derler I, Jardin I, Romanin C. Molecular mechanisms of STIM/ Orai communication. Am J Physiol Cell Physiol 2016;310:C643C662.

19. Kaufmann U, Kahlfuss S, Yang J, Ivanova E, Koralov SB, Feske S. Calcium signaling controls pathogenic Th17 cell-mediated inflammation by regulating mitochondrial function. Cell Metab 2019;29:1104-1118.

20. Feske S, Picard C, Fischer A. Immunodeficiency due to mutations in ORAIl and STIM1. Clin Immunol 2010;135:169-182.

21. Kim KD, Srikanth S, Tan YV, et al. Calcium signaling via Orail is essential for induction of the nuclear orphan receptor pathway to drive Th17 differentiation. J Immunol 2014;192:110-122.

22. Mehrotra P, Sturek M, Neyra JA, Basile DP. Calcium channel Orail promotes lymphocyte IL-17 expression and progressive kidney injury. J Clin Invest 2019;129:4951-4961.

23. Gaffen SL. Structure and signalling in the IL-17 receptor family. Nat Rev Immunol 2009;9:556-567.

24. Shen F, Gaffen SL. Structure-function relationships in the IL17 receptor: implications for signal transduction and therapy. Cytokine 2008;41:92-104.

25. Kuestner RE, Taft DW, Haran A, et al. Identification of the IL-17 
receptor related molecule IL-17RC as the receptor for IL-17F. $J$ Immunol 2007;179:5462-5473.

26. Biswas PS. IL-17 in renal immunity and autoimmunity. J Immunol 2018;201:3153-3159.

27. Cypowyj S, Picard C, Maródi L, Casanova JL, Puel A. Immunity to infection in IL-17-deficient mice and humans. Eur J Immunol 2012;42:2246-2254.

28. Sundac L, Dando SJ, Sullivan MJ, Derrington P, Gerrard J, Ulett GC. Protein-based profiling of the immune response to uropathogenic Escherichia coli in adult patients immediately following hospital admission for acute cystitis. Pathog Dis 2016;74:ftw062.

29. Sivick KE, Schaller MA, Smith SN, Mobley HL. The innate immune response to uropathogenic Escherichia coli involves IL-17A in a murine model of urinary tract infection. J Immunol 2010;184:2065-2075.

30. Olson PD, Hruska KA, Hunstad DA. Androgens enhance male urinary tract infection severity in a new model. J Am Soc Nephrol 2016;27:1625-1634.

31. Zychlinsky Scharff A, Rousseau M, Lacerda Mariano L, et al. Sex differences in IL-17 contribute to chronicity in male versus female urinary tract infection. JCI Insight 2019;5:e122998.

32. Huang W, Na L, Fidel PL, Schwarzenberger P. Requirement of interleukin-17A for systemic anti-Candida albicans host defense in mice. J Infect Dis 2004;190:624-631.

33. Ramani K, Jawale CV, Verma AH, Coleman BM, Kolls JK, Biswas PS. Unexpected kidney-restricted role for IL-17 receptor signaling in defense against systemic Candida albicans infection. JCI Insight 2018;3:e98241.

34. Shah K, Lee WW, Lee SH, et al. Dysregulated balance of Th17 and Th1 cells in systemic lupus erythematosus. Arthritis Res Ther 2010;12:R53.

35. Jakiela B, Kosałka J, Plutecka H, Bazan-Socha S, Sanak M, Musiał J. Facilitated expansion of Th17 cells in lupus nephritis patients. Clin Exp Immunol 2018;194:283-294.

36. Zickert A, Amoudruz P, Sundström Y, Rönnelid J, Malmström V, Gunnarsson I. IL-17 and IL-23 in lupus nephritis: association to histopathology and response to treatment. BMC Immunol 2015;16:7.

37. Crispín JC, Oukka M, Bayliss G, et al. Expanded double negative T cells in patients with systemic lupus erythematosus produce IL-17 and infiltrate the kidneys. J Immunol 2008;181:8761-8766.

38. Krebs CF, Paust HJ, Krohn S, et al. Autoimmune renal disease is exacerbated by S1P-receptor-1-dependent intestinal Th17 cell migration to the kidney. Immunity 2016;45:1078-1092.
39. Velden J, Paust HJ, Hoxha E, et al. Renal IL-17 expression in human ANCA-associated glomerulonephritis. Am J Physiol Renal Physiol 2012;302:F1663-F1673.

40. Nogueira E, Hamour S, Sawant D, et al. Serum IL-17 and IL23 levels and autoantigen-specific Th17 cells are elevated in patients with ANCA-associated vasculitis. Nephrol Dial Transplant 2010;25:2209-2217.

41. Wątorek E, Klinger M. IL-17A as a potential biomarker of IgA nephropathy. Pol Arch Med Wewn 2015;125:204-206.

42. Jen HY, Chuang YH, Lin SC, Chiang BL, Yang YH. Increased serum interleukin-17 and peripheral Th17 cells in children with acute Henoch-Schönlein purpura. Pediatr Allergy Immunol 2011;22:862-868.

43. Wang L, Li Q, Wang L, et al. The role of Th17/IL-17 in the pathogenesis of primary nephrotic syndrome in children. Kidney Blood Press Res 2013;37:332-345.

44. Liu LL, Qin Y, Cai JF, et al. Th17/Treg imbalance in adult patients with minimal change nephrotic syndrome. Clin Immunol 2011;139:314-320.

45. Loverre A, Tataranni T, Castellano G, et al. IL-17 expression by tubular epithelial cells in renal transplant recipients with acute antibody-mediated rejection. Am J Transplant 2011;11:12481259.

46. Hsieh HG, Loong CC, Lui WY, Chen A, Lin CY. IL-17 expression as a possible predictive parameter for subclinical renal allograft rejection. Transpl Int 2001;14:287-298.

47. de Menezes Neves PD, Machado JR, dos Reis MA, Faleiros AC, de Lima Pereira SA, Rodrigues DB. Distinct expression of interleukin 17 , tumor necrosis factor $\alpha$, transforming growth factor $\beta$, and forkhead box P3 in acute rejection after kidney transplantation. Ann Diagn Pathol 2013;17:75-79.

48. Millán O, Rafael-Valdivia L, San Segundo D, et al. Should IFN- $\gamma$, IL-17 and IL-2 be considered predictive biomarkers of acute rejection in liver and kidney transplant? Results of a multicentric study. Clin Immunol 2014;154:141-154.

49. Matignon M, Aissat A, Canoui-Poitrine F, et al. Th-17 alloimmune responses in renal allograft biopsies from recipients of kidney transplants using extended criteria donors during acute T cellmediated rejection. Am J Transplant 2015;15:2718-2725.

50. Chung BH, Kim KW, Kim BM, Doh KC, Cho ML, Yang CW. Increase of Th17 cell phenotype in kidney transplant recipients with chronic allograft dysfunction. PLoS One 2015;10:e0145258.

51. Maravitsa P, Adamopoulou M, Pistiki A, Netea MG, Louis K, Giamarellos-Bourboulis EJ. Systemic over-release of interleukin-17 in acute kidney injury after septic shock: clinical 
and experimental evidence. Immunol Lett 2016;178:68-76.

52. Coppock GM, Aronson LR, Park J, et al. Loss of IL-27R $\alpha$ results in enhanced tubulointerstitial fibrosis associated with elevated th17 responses. J Immunol 2020;205:377-386.

53. Chung BH, Kim KW, Sun IO, et al. Increased interleukin-17 producing effector memory $\mathrm{T}$ cells in the end-stage renal disease patients. Immunol Lett 2012;141:181-189.

54. Zhang C, Xiao C, Wang P, et al. The alteration of Th1/Th2/ Th17/Treg paradigm in patients with type 2 diabetes mellitus: relationship with diabetic nephropathy. Hum Immunol 2014; 75:289-296.

55. Niewczas MA, Pavkov ME, Skupien J, et al. A signature of circulating inflammatory proteins and development of endstage renal disease in diabetes. Nat Med 2019;25:805-813.

56. Madhur MS, Lob HE, McCann LA, et al. Interleukin 17 promotes angiotensin II-induced hypertension and vascular dysfunction. Hypertension 2010;55:500-507.

57. Yao W, Sun Y, Wang X, Niu K. Elevated serum level of interleukin 17 in a population with prehypertension. J Clin Hypertens (Greenwich) 2015;17:770-774.

58. Simundic T, Jelakovic B, Dzumhur A, et al. Interleukin 17A and toll-like receptor 4 in patients with arterial hypertension. Kidney Blood Press Res 2017;42:99-108.

59. Hosseini A, Dolati S, Hashemi V, Abdollahpour-Alitappeh M, Yousefi M. Regulatory T and T helper 17 cells: Their roles in preeclampsia. J Cell Physiol 2018;233:6561-6573.

60. Monin L, Gaffen SL. Interleukin 17 family cytokines: signaling mechanisms, biological activities, and therapeutic implications. Cold Spring Harb Perspect Biol 2018;10:a028522.

61. Koga T, Ichinose K, Tsokos GC. T cells and IL-17 in lupus nephritis. Clin Immunol 2017;185:95-99.

62. Gan PY, Chan A, Ooi JD, et al. Biologicals targeting T helper cell subset differentiating cytokines are effective in the treatment of murine anti-myeloperoxidase glomerulonephritis. Kidney Int 2019;96:1121-1133.

63. Gan PY, Steinmetz OM, Tan DS, et al. Th17 cells promote autoimmune anti-myeloperoxidase glomerulonephritis. J Am Soc Nephrol 2010;21:925-931.

64. Hünemörder S, Treder J, Ahrens S, et al. TH1 and TH17 cells promote crescent formation in experimental autoimmune glomerulonephritis. J Pathol 2015;237:62-71.

65. Summers SA, Odobasic D, Khouri MB, et al. Endogenous interleukin (IL)-17A promotes pristane-induced systemic autoimmunity and lupus nephritis induced by pristane. Clin Exp Immunol 2014;176:341-350.
66. Steinmetz OM, Summers SA, Gan PY, Semple T, Holdsworth SR, Kitching AR. The Th17-defining transcription factor ROR $\gamma t$ promotes glomerulonephritis. J Am Soc Nephrol 2011;22:472483.

67. Paust HJ, Turner JE, Riedel JH, et al. Chemokines play a critical role in the cross-regulation of Th1 and Th17 immune responses in murine crescentic glomerulonephritis. Kidney Int 2012;82:7283.

68. Tulone C, Giorgini A, Freeley S, Coughlan A, Robson MG. Transferred antigen-specific $\mathrm{T}(\mathrm{H}) 17$ but not $\mathrm{T}(\mathrm{H}) 1$ cells induce crescentic glomerulonephritis in mice. Am J Pathol 2011;179:2683-2690.

69. Steinmetz OM, Turner JE, Paust HJ, et al. CXCR3 mediates renal Th1 and Th17 immune response in murine lupus nephritis. J Immunol 2009;183:4693-4704.

70. Lu G, Zhang X, Shen L, et al. CCL20 secreted from IgA1stimulated human mesangial cells recruits inflammatory Th17 cells in IgA nephropathy. PLoS One 2017;12:e0178352.

71. Nakagiri T, Inoue M, Minami M, Shintani Y, Okumura M. Immunology mini-review: the basics of T(H)17 and interleukin-6 in transplantation. Transplant Proc 2012;44:1035-1040.

72. Chung BH, Yang CW, Cho ML. Clinical significance of Th17 cells in kidney transplantation. Korean J Intern Med 2018;33:860-866.

73. Nova-Lamperti E, Romano M, Christakoudi S, et al. Reduced TCR signaling contributes to impaired Th17 responses in tolerant kidney transplant recipients. Transplantation 2018;102:e10-e17.

74. Min SI, Ha J, Park CG, et al. Sequential evolution of IL-17 responses in the early period of allograft rejection. Exp Mol Med 2009;41:707-716.

75. Zhou Y, Yang X, Zhang H, Jiang J. The roles of T helper type 17/ regulatory T cells in acute rejection after liver transplantation in rats. Transplantation 2015;99:1126-1131.

76. Itoh S, Kimura N, Axtell RC, et al. Interleukin-17 accelerates allograft rejection by suppressing regulatory $\mathrm{T}$ cell expansion. Circulation 2011;124:S187-S196.

77. Mortazavi H, Soltani-Zangbar MS, Eghbal-Fard S, et al. Cytokine profile, Treg/Th17 cell frequency changes during different posttransplantational time points in patients undergoing renal transplantation. J Cell Physiol 2019;234:20935-20943.

78. Abadja F, Atemkeng S, Alamartine E, Berthoux F, Mariat C. Impact of mycophenolic acid and tacrolimus on Th17-related immune response. Transplantation 2011;92:396-403.

79. Chung BH, Kim BM, Doh KC, et al. Suppressive effect of 1a,25-dihydroxyvitamin D3 on Th17-immune responses in kidney transplant recipients with tacrolimus-based immunosuppression. Transplantation 2017;101:1711-1719. 
80. Kinsey GR, Sharma R, Okusa MD. Regulatory T cells in AKI. J Am Soc Nephrol 2013;24:1720-1726.

81. Gharaie Fathabad S, Kurzhagen JT, Sadasivam M, et al. T lymphocytes in acute kidney injury and repair. Semin Nephrol 2020;40:114-125.

82. Yokota N, Burne-Taney M, Racusen L, Rabb H. Contrasting roles for STAT4 and STAT6 signal transduction pathways in murine renal ischemia-reperfusion injury. Am J Physiol Renal Physiol 2003;285:F319-F325.

83. de Bragança AC, Volpini RA, Mehrotra P, Andrade L, Basile DP. Vitamin D deficiency contributes to vascular damage in sustained ischemic acute kidney injury. Physiol Rep 2016; 4:e12829.

84. Mehrotra P, Collett JA, McKinney SD, Stevens J, Ivancic CM, Basile DP. IL-17 mediates neutrophil infiltration and renal fibrosis following recovery from ischemia reperfusion: compensatory role of natural killer cells in athymic rats. Am J Physiol Renal Physiol 2017;312:F385-F397.

85. Lee JW, Bae E, Kwon SH, et al. Transcriptional modulation of the T helper 17/interleukin 17 axis ameliorates renal ischemiareperfusion injury. Nephrol Dial Transplant 2019;34:1481-1498.

86. Mehrotra P, Ullah MM, Collett JA, et al. Mutation of ROR $\gamma \mathrm{T}$ reveals a role for Th17 cells in both injury and recovery from renal ischemia-reperfusion injury. Am J Physiol Renal Physiol 2020;319:F796-F808.

87. Luo CJ, Luo F, Zhang L, et al. Knockout of interleukin-17A protects against sepsis-associated acute kidney injury. Ann Intensive Care 2016;6:56.

88. Chan AJ, Alikhan MA, Odobasic D, et al. Innate IL-17A-producing leukocytes promote acute kidney injury via inflammasome and Toll-like receptor activation. Am J Pathol 2014;184:1411-1418.

89. Wang F, Yin J, Lin Y, et al. IL-17C has a pathogenic role in kidney ischemia/reperfusion injury. Kidney Int 2020;97:1219-1229.

90. Ullah MM, Basile DP. Role of renal hypoxia in the progression from acute kidney injury to chronic kidney disease. Semin Nephrol 2019;39:567-580.

91. Mehrotra P, Patel JB, Ivancic CM, Collett JA, Basile DP. Th-17 cell activation in response to high salt following acute kidney injury is associated with progressive fibrosis and attenuated by AT-1R antagonism. Kidney Int 2015;88:776-784.

92. Pechman KR, Basile DP, Lund H, Mattson DL. Immune suppression blocks sodium-sensitive hypertension following recovery from ischemic acute renal failure. Am J Physiol Regul Integr Comp Physiol 2008;294:R1234-R1239.

93. Kim YG, Kim EY, Ihm CG, et al. Gene polymorphisms of interleukin-17 and interleukin-17 receptor are associated with end-stage kidney disease. Am J Nephrol 2012;36:472-477.

94. Chi HH, Hua KF, Lin YC, et al. IL-36 signaling facilitates activation of the NLRP3 inflammasome and IL-23/IL-17 axis in renal inflammation and fibrosis. J Am Soc Nephrol 2017;28:2022-2037.

95. Rodrigues-Díez R, Rodrigues-Díez RR, Rayego-Mateos S, et al. The C-terminal module IV of connective tissue growth factor is a novel immune modulator of the Th17 response. Lab Invest 2013;93:812-824.

96. Ramani K, Tan RJ, Zhou D, et al. IL-17 receptor signaling negatively regulates the development of tubulointerstitial fibrosis in the kidney. Mediators Inflamm 2018;2018:5103672.

97. Pindjakova J, Hanley SA, Duffy MM, et al. Interleukin-1 accounts for intrarenal Th17 cell activation during ureteral obstruction. Kidney Int 2012;81:379-390.

98. Xu Y, Lin H, Zheng W, et al. Matrine ameliorates adriamycininduced nephropathy in rats by enhancing renal function and modulating Th17/Treg balance. Eur J Pharmacol 2016;791:491501.

99. Muallem G, Aronson L, Hunter CA, et al. The endogenous regulator IL-27 suppresses Th2 and Th17 responses in the kidney to ameliorate renal fibrosis in a model of obstructive kidney disease. J Immunol 2017;198(1 Suppl):220.17.

100. Lavoz C, Rayego-Mateos S, Orejudo M, et al. Could IL-17A be a novel therapeutic target in diabetic nephropathy? J Clin Med 2020;9:272.

101. Emamaullee JA, Davis J, Merani S, et al. Inhibition of Th17 cells regulates autoimmune diabetes in NOD mice. Diabetes 2009; 58:1302-1311.

102. Kim SM, Lee SH, Lee A, et al. Targeting Thelper 17 by mycophenolate mofetil attenuates diabetic nephropathy progression. Transl Res 2015;166:375-383.

103. Ma J, Li YJ, Chen X, Kwan T, Chadban SJ, Wu H. Interleukin 17A promotes diabetic kidney injury. Sci Rep 2019;9:2264.

104. Lavoz C, Matus YS, Orejudo M, et al. Interleukin-17A blockade reduces albuminuria and kidney injury in an accelerated model of diabetic nephropathy. Kidney Int 2019;95:1418-1432.

105. Rodríguez-Iturbe B, Vaziri ND, Herrera-Acosta J, Johnson RJ. Oxidative stress, renal infiltration of immune cells, and saltsensitive hypertension: all for one and one for all. Am J Physiol Renal Physiol 2004;286:F606-F616.

106. Abais-Battad JM, Rudemiller NP, Mattson DL. Hypertension and immunity: mechanisms of $\mathrm{T}$ cell activation and pathways of hypertension. Curr Opin Nephrol Hypertens 2015;24:470-474. 
107. Abais-Battad JM, Lund H, Fehrenbach DJ, Dasinger JH, Mattson DL. Rag1-null Dahl SS rats reveal that adaptive immune mechanisms exacerbate high protein-induced hypertension and renal injury. Am J Physiol Regul Integr Comp Physiol 2018;315:R28-R35.

108. Rodríguez-Iturbe B, Pons H, Quiroz Y, et al. Mycophenolate mofetil prevents salt-sensitive hypertension resulting from angiotensin II exposure. Kidney Int 2001;59:2222-2232.

109. Wade B, Petrova G, Mattson DL. Role of immune factors in angiotensin II-induced hypertension and renal damage in Dahl salt-sensitive rats. Am J Physiol Regul Integr Comp Physiol 2018;314:R323-R333.

110. Amador CA, Barrientos V, Peña J, et al. Spironolactone decreases DOCA-salt-induced organ damage by blocking the activation of $\mathrm{T}$ helper 17 and the downregulation of regulatory T lymphocytes. Hypertension 2014;63:797-803.

111. Chiasson VL, Pakanati AR, Hernandez M, Young KJ, Bounds KR, Mitchell BM. Regulatory T-cell augmentation or interleukin-17 inhibition prevents calcineurin inhibitor-induced hypertension in mice. Hypertension 2017;70:183-191.

112. Cornelius DC, Hogg JP, Scott J, et al. Administration of interleukin-17 soluble receptor C suppresses TH17 cells, oxidative stress, and hypertension in response to placental ischemia during pregnancy. Hypertension 2013;62:1068-1073.

113. Rudemiller NP, Crowley SD. Interactions between the immune and the renin-angiotensin systems in hypertension. Hypertension 2016;68:289-296.

114. Faraco G, Brea D, Garcia-Bonilla L, et al. Dietary salt promotes neurovascular and cognitive dysfunction through a gut-initiated TH17 response. Nat Neurosci 2018;21:240-249.

115. Luo T, Ji WJ, Yuan F, et al. Th17/Treg imbalance induced by dietary salt variation indicates inflammation of target organs in humans. Sci Rep 2016;6:26767.

116. Dar HY, Singh A, Shukla P, et al. High dietary salt intake correlates with modulated Th17-Treg cell balance resulting in enhanced bone loss and impaired bone-microarchitecture in male mice. Sci Rep 2018;8:2503.

117. Haase S, Wilck N, Kleinewietfeld M, Müller DN, Linker RA. Sodium chloride triggers Th17 mediated autoimmunity. $J$ Neuroimmunol 2019;329:9-13.

118. Kleinewietfeld M, Manzel A, Titze J, et al. Sodium chloride drives autoimmune disease by the induction of pathogenic TH17 cells. Nature 2013;496:518-522.

119. Schatz V, Neubert P, Schröder A, et al. Elementary immunology: $\mathrm{Na}+$ as a regulator of immunity. Pediatr Nephrol 2017;32:201-
210.

120. Evans RDR, Antonelou M, Sathiananthamoorthy S, et al. Inherited salt-losing tubulopathies are associated with immunodeficiency due to impaired IL-17 responses. Nat Commun 2020;11:4368.

121. Liu J, Krautzberger AM, Sui SH, et al. Cell-specific translational profiling in acute kidney injury. J Clin Invest 2014;124:12421254.

122. Norlander AE, Saleh MA, Kamat NV, et al. Interleukin-17A regulates renal sodium transporters and renal injury in angiotensin II-induced hypertension. Hypertension 2016;68:167-174.

123. Kamat NV, Thabet SR, Xiao L, et al. Renal transporter activation during angiotensin-II hypertension is blunted in interferon- $\gamma-/$ and interleukin-17A-/- mice. Hypertension 2015;65:569-576.

124. Venkatachalam MA, Weinberg JM, Kriz W, Bidani AK. Failed tubule recovery, AKI-CKD transition, and kidney disease progression. J Am Soc Nephrol 2015;26:1765-1776.

125. Kirita Y, Wu H, Uchimura K, Wilson PC, Humphreys BD. Cell profiling of mouse acute kidney injury reveals conserved cellular responses to injury. Proc Natl Acad Sci US A 2020;117:15874-15883.

126. Weng CH, Li YJ, Wu HH, et al. Interleukin-17A induces renal fibrosis through the ERK and Smad signaling pathways. Biomed Pharmacother 2020;123:109741.

127. Nguyen H, Chiasson VL, Chatterjee P, Kopriva SE, Young KJ, Mitchell BM. Interleukin-17 causes Rho-kinase-mediated endothelial dysfunction and hypertension. Cardiovasc Res 2013;97:696-704.

128. Orejudo M, García-Redondo AB, Rodrigues-Diez RR, et al. Interleukin-17A induces vascular remodeling of small arteries and blood pressure elevation. Clin Sci (Lond) 2020;134:513527.

129. Roussel L, Houle F, Chan C, et al. IL-17 promotes p38 MAPKdependent endothelial activation enhancing neutrophil recruitment to sites of inflammation. J Immunol 2010;184:45314537.

130. Yuan S, Zhang S, Zhuang Y, Zhang H, Bai J, Hou Q. Interleukin-17 stimulates STAT3-mediated endothelial cell activation for neutrophil recruitment. Cell Physiol Biochem 2015;36:2340-2356.

131. Wojkowska DW, Szpakowski P, Glabinski A. Interleukin 17A promotes lymphocytes adhesion and induces CCL2 and CXCL1 release from brain endothelial cells. Int J Mol Sci 2017;18:1000.

132. Kramann R, DiRocco DP, Humphreys BD. Understanding the origin, activation and regulation of matrix-producing myofibroblasts for treatment of fibrotic disease. J Pathol 2013;231:273-289.

133. Evasovic JM, Singer CA. Regulation of IL-17A and implications for TGF- $\beta 1$ comodulation of airway smooth muscle remodeling 
in severe asthma. Am J Physiol Lung Cell Mol Physiol 2019;316: L843-L868.

134. Lauridsen HM, Pellowe AS, Ramanathan A, et al. Tumor necrosis factor- $\alpha$ and IL-17A activation induces pericyte-mediated basement membrane remodeling in human neutrophilic dermatoses. Am J Pathol 2017;187:1893-1906.

135. Liu R, Lauridsen HM, Amezquita RA, et al. IL-17 promotes neutrophil-mediated immunity by activating microvascular pericytes and not endothelium. J Immunol 2016;197:2400-2408.

136. Zhang J, Qiao Q, Liu M, et al. IL-17 promotes scar formation by inducing macrophage infiltration. Am J Pathol 2018;188:16931702.

137. Ge S, Hertel B, Susnik N, et al. Interleukin 17 receptor A modulates monocyte subsets and macrophage generation in vivo. PLoS One 2014;9:e85461.

138. de la Paz Sánchez-Martínez M, Blanco-Favela F, Mora-Ruiz MD, Chávez-Rueda AK, Bernabe-García M, Chávez-Sánchez L. IL-17-differentiated macrophages secrete pro-inflammatory cytokines in response to oxidized low-density lipoprotein. Lipids Health Dis 2017;16:196.

139. Nishikawa K, Seo N, Torii M, et al. Interleukin-17 induces an atypical M2-like macrophage subpopulation that regulates intestinal inflammation. PLoS One 2014;9:e108494.

140. Zizzo G, Cohen PL. IL-17 stimulates differentiation of human anti-inflammatory macrophages and phagocytosis of apoptotic neutrophils in response to IL-10 and glucocorticoids. J Immunol 2013;190:5237-5246.

141. Ramani K, Zhou D, Tan R, Liu Y, Gaffen S, Biswas PS. Disruption of interleukin-17 receptor A (IL-17RA) gene in mice aggravates renal interstitial fibrosis in obstructive nephropathy. J Immunol 2016;196(1 Suppl):51.24.

142. Krebs CF, Lange S, Niemann G, et al. Deficiency of the interleukin 17/23 axis accelerates renal injury in mice with deoxycorticosterone acetate+angiotensin ii-induced hypertension. Hypertension 2014;63:565-571.

143. Sun B, Wang H, Zhang L, et al. Role of interleukin 17 in TGF- $\beta$ signaling-mediated renal interstitial fibrosis. Cytokine 2018;106: 80-88.

144. Corneth OBJ, Schaper F, Luk F, et al. Lack of IL-17 Receptor A signaling aggravates lymphoproliferation in C57BL/6 lpr mice. Sci Rep 2019;9:4032.

145. Mohamed R, Jayakumar C, Chen F, et al. Low-dose IL-17 therapy prevents and reverses diabetic nephropathy, metabolic syndrome, and associated organ fibrosis. J Am Soc Nephrol 2016;27:745-765.

146. Chiricozzi A, Krueger JG. IL-17 targeted therapies for psoriasis. Expert Opin Investig Drugs 2013;22:993-1005.

147. Tian C, Du L, Zhou Y, Li M. Store-operated CRAC channel inhibitors: opportunities and challenges. Future Med Chem 2016;8:817-832. 